GNIP ONDJFM monthly values) is plotted against the $\delta^{18} \mathrm{O}$ of reconstructed winter drip water and shown in Figure 4, which shows a significant correlation with $r^{2}=$ 0.47 and a slope of $\approx 1$. Such good correspondence between the instrumental precipitation isotope record and the oxygen isotope signal encoded in speleothem calcite shows that precipitation isotope time series can successfully be reconstructed from speleothem calcite and is an important milestone in producing a calibrated $\delta^{18} \mathrm{O}$-climate transfer function, which can then be applied to longer speleothem records.

\section{Conclusions}

Monitoring of cave processes over multiannual time periods provides essential insight into the way that speleothems record climate, and is an important step towards defining the response times of the cave and speleothem "recording systems" to changes in local climate and water balance. Close monitoring of just three sites in Gibraltar reveal significant differences in drip hydrology and speleothem forming processes, and to properly understand the drip water isotope evolution it could be necessary to monitor over 5-10 hydrological cycles to reveal the long term patterns. Monitoring for shorter periods still provides vital insight into the local processes that may bias the isotopic signal, and provides a framework for developing the calibrated $\delta^{18} \mathrm{O}$-climate transfer functions that are necessary to unlock the quantitative records that speleothems are capable of providing.

\section{Acknowledgements}

We thank John Ballestrino and Richard Durrell for help with cave sampling and Dylan Sheriff, the Gibraltar Tourist Office, Tito Vallejo and the guides of St. Michaels Cave for their coopera- tion. Thanks to Jacqui Duffet and Rebecca Fisher for help with the analyses. Many of the ideas in this work were developed through discussion with Tim Atkinson and lan Fairchild.

\section{References}

Bar-Matthews, M., Ayalon, A., Matthews, A., Sass, E. and Halicz, L., 1996 Carbon and oxygen isotope study of the active water-carbonate system in a karstic Mediterranean cave: Implications for paleoclimate research in semiarid regions, Geochimica Et Cosmochimica Acta, 60 (2): 337-347.

Fairchild, I.J., Smith, C.L., Baker, A., Fuller, L., Spötl, C. Mattey, D. McDermott, F. and EIMF, 2005: Modification and preservation of environmental signals in speleothems, Earth Science Reviews, 75: 153-195.

Mattey, D., Lowry, D., Duffet, J., Hodge, E. and Frisia, S., 2008: A 56 year seasonally resolved oxygen and carbon isotope record from a modern Gibraltar speleothem: reconstructed dripwater and relationship to local precipitation, Earth and Planetary Science Letters, 269: 80-95

McDermott, F., 2004: Palaeo-climate reconstruction from stable isotope variations in speleothems: a review, Quaternary Science Reviews, 23(7-8): 901-918

Spötl, C., Fairchild, I.J. and Tooth, A.F., 2005: Cave air control on dripwate geochemistry, Obir Caves (Austria): Implications for speleothem deposition in dynamically ventilated caves, Geochimica Et Cosmochimica Acta, 69(10): 2451-2468.

For full references please consult:

www.pages-igbp.org/products/newsletters/ref2008_3.html

\title{
Understanding climate proxies in southwest-Australian speleothems
}

\author{
Pauline C. Treble ${ }^{1,2}$, I.J. Fairchild ${ }^{3}$ and M.J. Fischer ${ }^{2}$
}

${ }^{1}$ Research School of Earth Sciences, Australian National University, Canberra; Pauline.Treble@anu.edu.au

${ }^{2}$ Institute for Environmental Research, Australian Nuclear Science and Technology Organization; ${ }^{3}$ School of Geography, Earth and Environmental Sciences, University of Birmingham, UK

There are two avenues for comparing speleothem-derived climate proxy data against instrumental climate measurements: Via speleothems that have grown through the $20^{\text {th }}$ century, and by carrying out dripwater monitoring studies. Both provide opportunities to investigate how speleothem geochemistry responds to changes in intra- and inter-annual variations in climatic parameters. Much work remains to understand these processes in general, and it is becoming increasingly apparent that such exercises are necessary to understand processes in individual caves, owing to the broad variation in climatic, geological and geomorphic environments that host speleothems. Here, we provide an overview of recent research findings from several cave sites in southwest Australia. Multiple geochemical proxies $\left(\delta^{18} \mathrm{O}\right.$, $\delta^{13} \mathrm{C}, \mathrm{P}, \mathrm{U}, \mathrm{Mg}, \mathrm{Sr}, \mathrm{Ba}$ and $\mathrm{Na}$ ) from calcite speleothems from this region have provided the longest duration (80 complete years from 1911-1992) calibration dataset between speleothem geochemistry and the instrument climate record. We use this case study of modern speleothem $\delta^{18} \mathrm{O}$ and trace elements to provide examples of techniques for calibration and to highlight the importance of carrying out such investigations.

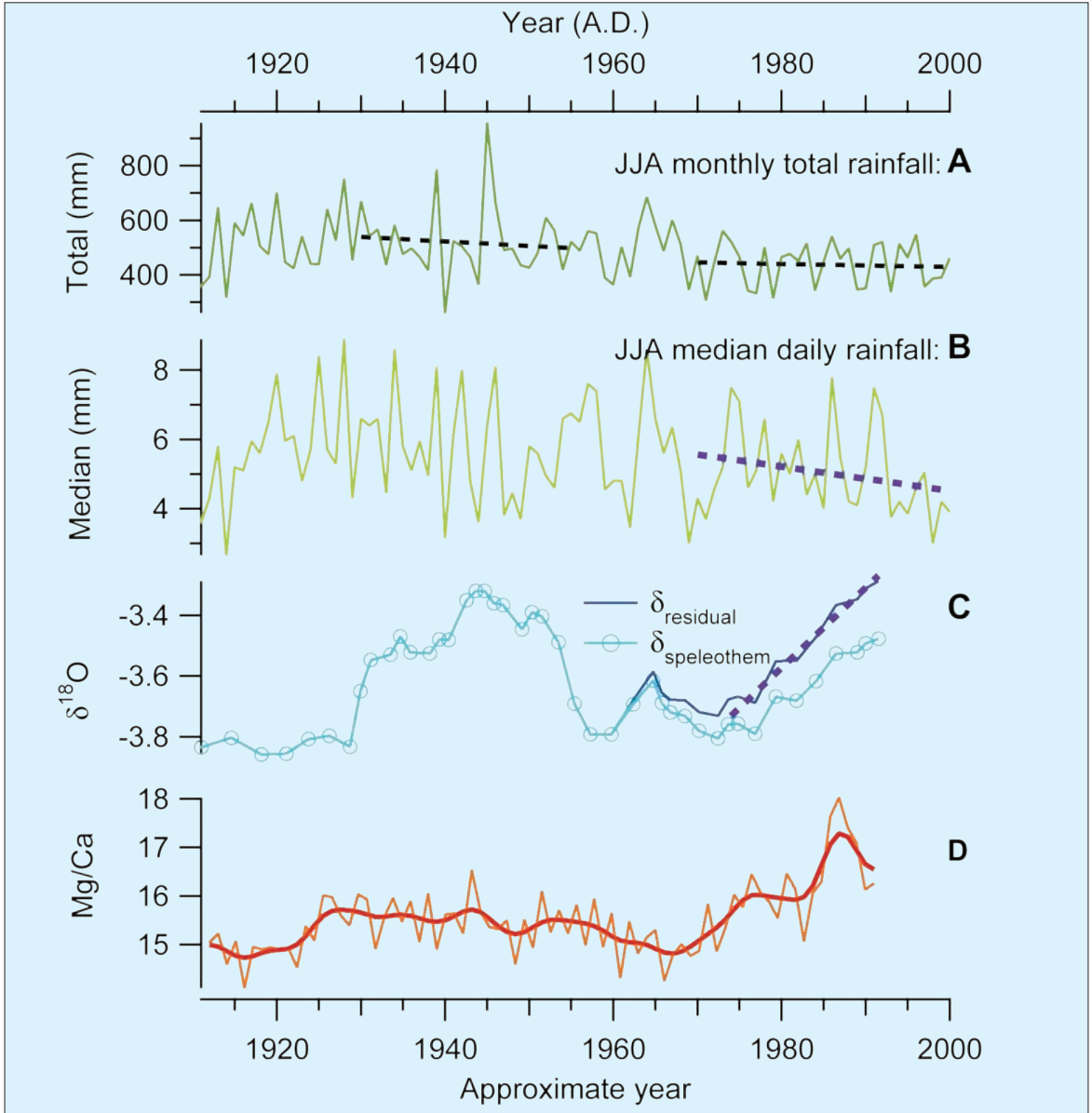

Figure 1: $\boldsymbol{A})$ Perth total June-August rainfall (instrumental), $\boldsymbol{B}$ ) median daily rainfall (instrumental), $\boldsymbol{C}$ ) Moondyne Cave speleothem $\delta^{18} \mathrm{O}$ and $\left.\mathbf{D}\right) \mathrm{Mg} / \mathrm{Ca}$ atios $(\mu \mathrm{mol} / \mathrm{mol})$. Speleothem $\delta^{18} \mathrm{O}(\delta, \quad)$ is corrected $(\delta$,$) for the rise$ in mean temperature. Speleothem $\delta^{18} \mathrm{O}$ increases during 1930-55, owing to a change in moisture source region (Fischer and Treble, in press). 


\section{Southwest Australia}

Southwest Australia provides an ideal location for comparing speleothem records with instrumental data. Caves in this region typically underlie native forests that have not been significantly altered by European settlement. Caves are hosted in porous Pleistocene calcarenite, resulting in a relatively smooth transfer of drip water and its chemical signal by predominantly seepage-type flow. Southwest Australia has a Mediterranean-type climate with distinctly wet winters and dry summers, which give rise to clear seasonal responses in drip water chemistry. On the longer term, rainfall has markedly decreased across the southwestern corner of Western Australia from about 1970 (Allan and Haylock, 1993; Fig. $1 A, B)$, providing a test for the geochemical record. This rainfall decrease was recorded within the growth interval of a stalagmite (MND-S1) that grew in Moondyne Cave between 1911 and 1992 (Treble et al., 2003; 2005). Here, we provide a review of these data, including new findings and drip water data from a nearby cave.

\section{Oxygen isotopes}

The instrumental record shows that the mean annual temperature in southwest Australia rose by approx. $0.6^{\circ} \mathrm{C}$ from the mid-1950s (Indian Ocean Climate Initiative, 2002), until the stalagmite MND-S1 was removed in 1992. The effect of this temperature rise on the $\delta^{18} \mathrm{O}$ of the stalagmite (calculated using the temperature-dependent fractionation of ${ }^{18} \mathrm{O} /{ }^{16} \mathrm{O}$ at calcification $\left(-0.23 \%{ }^{\circ}{ }^{\circ} \mathrm{C}\right.$; O'Neil et al., 1969)) was subtracted from the $\delta^{18} \mathrm{O}$ data to produce a record reflecting variation in rainfall $\delta^{18} \mathrm{O}$ trends between 1911 and 1992 (Fig. 1C). Speleothem $\delta^{18} \mathrm{O}$ rose after 1970, which is consistent with the recorded decrease in rainfall (Treble et al., 2005). This result is expected based on the inverse relationship between rainfall $\delta^{18} \mathrm{O}$ and amount determined from one year of daily rainfall sampling in 2000-01 (12 km from Moondyne Cave; Treble et al., 2005). A common assumption with climate proxies is that one can apply short-interval calibrations to interpret trends in proxy data back in time. However, MND-S1 showed that this simple inverse relationship between rainfall amount and $\delta^{18} \mathrm{O}$ has not been consistent through time, evidenced by the higher $\delta^{18} \mathrm{O}$ values between 1930 1955 when there was no measured decrease in rainfall.

This key finding led to a recent investigation where the simple rainfall amount$\delta^{18} \mathrm{O}$ regression model was improved to include interannual climate variance (Fischer and Treble, in press). The new model was modulated by dominant modes of interannual climate variability or climate indices. The dominant interannual modes are calculated as the principal components of sea level pressure over the period 1850-2004 (for which sea level pressure data are available; Allan and Ansell, 2006). In the winter in the southern hemisphere extratropics, these principal components (i.e., dominant modes) of climate variability describe major zonal and meridional pressure anomalies between, and in, the mid- to high-latitudes. The new model produced a positive shift in $\delta^{18} \mathrm{O}$ between 1930-55, similar to that in the speleothem record. This suggests that the dominant modes of interannual variability can cause shifts in vapor-source regions (or other effects) that can affect $\delta^{18} \mathrm{O}$ independent of amount-type effects.

In southwest Australia, it appears that the interannual mode most responsible for isotopic changes related to vapor source is Zonal Wave 1 (ZW1). ZW1 is a persistent zonal pressure anomaly between the South Pacific Ocean and the South Indian/ Atlantic Oceans. An empirical orthogonal function (EOF)-based reconstruction of ZW1 over the last century suggests that, for southwest Australia, a negative ZW1 state from 1930-55 favored the advection of ${ }^{18} \mathrm{O}$-enriched moisture from low latitudes, while a positive ZW1 state post1970 resulted in more ${ }^{18} \mathrm{O}$-depleted moisture advected from the sub-polar region (Fischer and Treble, in press).

As a result, we now have an improved regression model for $\delta^{18} \mathrm{O}$ rainfall in southwest Australia that replicates key patterns at daily to inter-decadal timescales. This is a statistical forward model and thus it can be used to compare paleoclimate simulations to proxy data. The inversion of the model will require a multi-proxy approach (e.g., isotopes and trace elements), because the new model relies on two predic- tors $\left(\delta^{18} \mathrm{O}\right.$ depends on both precipitation amount and vapor source).

\section{Speleothem trace elements}

A suite of trace elements was also investigated in speleothem MND-S1 (Treble et al., 2003). Of these, annual speleothem Mg and $P$ concentrations were found to clearly record the rainfall decrease from 1970: Mg increased and P decreased (Fig. 1D; Mg only) but were unaffected by the change in vapor source in the 1930-55 period. Empirically, therefore, the trace elements are able to provide a distinction between the two episodes, which could be applied further back in time. However, the use of empirical relationships without an understanding of mechanisms is unlikely to be a sufficiently robust approach. Annual trace element cycles in the Moondyne speleothem provide evidence for mechanisms but there is a need for drip water studies too. Since Moondyne Cave has become largely dry since the late 1990s and only small areas contain perennially active dripping stalactites, this component of the study was conducted at Golgotha Cave, 20 km away.

Cave drip waters in Golgotha Cave were measured at 4 sites within the cave from July 2005. Drip water $\mathrm{Mg} / \mathrm{Ca}$ ratios display clear seasonal cycles at all sites (Fig. 2; site 1B shown) similar in form to the annual Mg cycles measured in speleothem MND-S1. In principle, such cycles can be caused by varying amounts of prior calcite precipitation (PCP; see Fairchild et al., 2000): The more calcite precipitated from solution before reaching the stalagmite (in the aquifer or on the stalactite tip), the lower the Ca solution concentration and the higher the $\mathrm{Mg} / \mathrm{Ca}$ in the solution and the resulting stalagmite. Initially, this was considered to be a simple response to the seasonal drying of the aquifer, leading to high $\mathrm{Mg} / \mathrm{Ca}$ in austral summer (Treble et

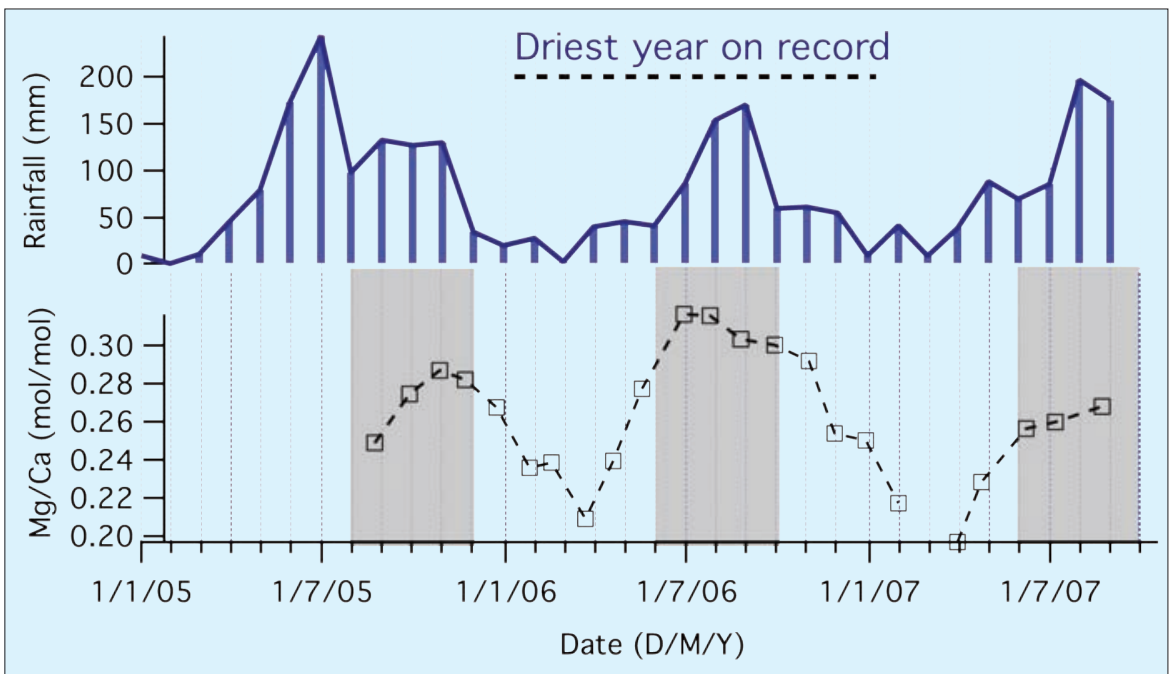

Figure 2: Monthly rainfall and drip water Mg/Ca ratios (mol/mol) for site 1 B in Golgotha Cave. Gray shading indicates months when drip water saturation indices $\left(\mathrm{CaCO}_{3}\right)$ are $\geq 0.2$ 
al., 2003) but the drip water study suggests otherwise. Drip water $\mathrm{Mg} / \mathrm{Ca}$ ratios are in fact higher in the wet winter months than summer, and tracing with $\mathrm{O}$ isotopes does not suggest that this is due to a seasonal lag. Rather, we interpret from seasonal variations in $\mathrm{pH}$ and alkalinity data that cave $\mathrm{PCO}_{2}$ is modulating seasonal $\mathrm{CaCO}_{3}$ saturation and hence inducing more PCP in the winter; the $\mathrm{PCO}_{2}$ variations also have the consequence that speleothem deposition in Golgotha Cave predominantly occurs during the winter/spring months. In more recent work, we have also established that $\mathrm{PCO}_{2}$ (via solution $\mathrm{pH}$ ) is the strongest influence on sulfate incorporation and, hence, we propose that sulfate profiles can be used to identify $\mathrm{PCO}_{2}$ controls. The $\mathrm{PCO}_{2}$ variations may also have a specific interpretation in terms of seasonality (cf., the Austrian Obir cave where low $\mathrm{PCO}_{2}$ reflects strong incoming air circulation at low winter temperatures; Spötl et al., 2005).

However, at Golgotha Cave we also observe that the highest $\mathrm{Mg} / \mathrm{Ca}$ ratios were reached during 2006 (Fig. 2), which was the driest year on record. This implies that the effect of residence time on this process is also important on interannual timescales (cf., McDonald et al., 2004) and can possibly be distinguished from the seasonal $\mathrm{PCO}_{2}$ effect. We are currently working on identifying the specific processes in relation to $\mathrm{Mg}$ sources that lead to these residence-time effects, in order to gain more confidence in the expected range of values that can be attributed to it under presentday conditions.

\section{Note}

Moondyne Cave stable isotope data is available for download from www.ncdc.noaa.gov/paleo/ speleothem.html

\section{References}

Fairchild, I., Borsato, A., Tooth, A., Frisia, S., Hawkesworth, C.J., Huang, Y. McDermott, F. and Spiro, B., 2000: Controls on trace element (Sr-Mg) compositions of carbonate cave waters: implications for speleothem climatic records, Chemical Geology, 166: 255-269.

Fischer, M. and Treble, P., in press: Calibrating climate- $\delta^{18} 0$ regression models for the interpretation of high-resolution speleothem $\delta^{18} 0$ time series, Journal of Geophysical Research (Atmospheres doi:10.1029/2007JD009694).

McDonald, J., Drysdale, R. and Hill, D., 2004: The 2002-2003 El Niño recorded in Australian cave drip waters: Implications for reconstructing rainfall histories using stalagmites, Geophysical Research Letters, 31: L22202, doi:10.1029/2004GL020859.

Treble, P., Shelley, J., and Chappell, J., 2003: Comparison of highresolution sub-annual records of trace elements in a modern (1911-1992) speleothem with instrumental climate data from southwest Australia, Earth and Planetary Science Letters, 216 141-153.

Treble, P., Chappell, J., Gagan, M. Harrison, T. and McKeegan, K., 2005: In situ measurement of seasonal $\delta^{18} 0$ variations and analysis of isotopic trends in a modern speleothem from southwest Australia, Earth and Planetary Science Letters, 233: 17-32.

For full references please consult:

www.pages-igbp.org/products/newsletters/ref2008_3.html

\section{Temperature and precipitation records from stalagmites grown under disequilibrium conditions: A first approach}

Christian Mühlinghaus, D. Scholz and A. Manginı

Heidelberg Academy of Sciences, Germany; christian.muehlinghaus@iup.uni-heidelberg.de

A variety of climate archives are studied to reconstruct past variations in Earth's climate. Recently, stalagmites have come into focus, due to their long, continuous growth periods and improved dating techniques. These archives provide high-resolution stable carbon $\left(\delta^{13} \mathrm{C}\right)$ and oxygen $\left(\delta^{18} \mathrm{O}\right)$ isotope profiles, which record information about climate-related parameters at the time of growth. While the $\delta^{18} \mathrm{O}$ of stalagmites grown under conditions of isotopic equilibrium depend on the $\delta^{18} \mathrm{O}$ value of the drip water and the cave temperature, the interpretation of stable oxygen isotopes from stalagmites grown under disequilibrium conditions is more difficult, due to the additional influence of the drip interval (i.e., the time between two subsequent drops feeding the stalagmite) on the isotope signal. Stalagmites that demonstrably grew under disequilibrium conditions, as indicated by a positive correlation between $\delta^{13} \mathrm{C}$ and $\delta^{18} \mathrm{O}$ along individual growth layers (Hendy tests), have traditionally been rejected from intensive research. However, a quantitative description of disequilibrium fractionation effects might enable the reconstruction of both temperature and drip interval from isotope profiles of these stalagmites.

Here, we present a numerical model (Combined Stalagmite Model; CSM) that calculates variations in temperature and precipitation from the isotope profiles from along the growth axis and individual growth layers, as well as the age-depth re- lation of stalagmites grown under conditions of isotopic disequilibrium.

\section{Model parameters}

The CSM is based on the inversion and combination of previously developed models. These are growth models (Dreybrodt, 1999; Kaufmann and Dreybrodt, 2004; Mühlinghaus et al., 2007) and isotope models that calculate the isotopic enrichment of carbon and oxygen, both along the growth axis and individual growth layers, assuming an irreversible Rayleigh fractionation process (i.e., the irreversible removal of $\mathrm{CO}_{2}$ through degassing and $\mathrm{CaCO}_{3}$ through precipitation, from the solution layer on top of the stalagmite) (Mühlinghaus et al., 2007; submitted). The models include the most important parameters describing the cave system and the overlying soil, such as temperature, water supply, the isotopic composition of the drip water, the partial $\mathrm{CO}_{2}$ pressure of the soil and the cave atmosphere, and the mixing coefficient, which describes mixing between the impinging drop and the existing solution layer.

The idea of the CSM is based on the consideration that the proxies (i.e., growth rate, $\delta^{13} \mathrm{C}$ and $\delta^{18} \mathrm{O}$ profiles), which are common stalagmite data sets, show different dependencies on the model parameters. Due to their high temporal resolution, the most important data sets are the carbon and oxygen profile along the growth axis. While $\delta^{13} \mathrm{C}$ reveals a strong dependence on drip interval but only a weak one on temperature, $\delta^{18} \mathrm{O}$ is influenced by both parameters (Mühlinghaus et al., submitted). Thus , a drip interval signal can be extracted from the carbon isotope profile, which is in turn used to correct the oxygen isotope profile for the influence of the drip interval, in order to obtain the temperature information.

\section{Model description}

To determine the characteristics of temperature and precipitation using the CSM, some simplification of the model parameters need to be made. Firstly, all parameters (except temperature and drip interval) are assumed to stay constant over the whole growth period of the stalagmite. This is a major simplification for parameters such as the isotopic composition of the drip water, which indeed shows temporal variations due to its correlation to temperature, for instance. For other parameters, like the mixing coefficient, this approximation may only disguise small temporal variations, which can be neglected in this first approach.

This simplification enables the CSM to run with only two input variables: The mean $\delta^{13} \mathrm{C}$ value of the drip water and the temperature at any point of time during the growth period of the stalagmite (e.g., the recent cave temperature). This yields a temperature and drip interval record of high temporal resolution. For the other parameters, such as the $\mathrm{CO}_{2}$ partial pres-

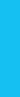

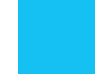

